Original

\title{
Comparison of occurrence of oro-maxillo-facial tumor types in different regions of the People's Republic of China
}

\author{
Kayo Kuyama*, Hirotsugu Yamamoto*, Motoi Morimoto ${ }^{\S}$, N. Meng ${ }^{\dagger}$, \\ Z. Liang ${ }^{\dagger}$ and Seigo Kobayashi ${ }^{*}$ \\ * Department of Oral Pathology, Nihon University School of Dentistry at Matsudo, Chiba 271-8587 \\ $\S$ Nihon University Research Center, Tokyo 102-8275 \\ $\dagger$ Department of Oral Pathology, Guangxi Medical College, Nanning, The People's Republic of China \\ $\$$ Department of Dental Health, Nihon University School of Dentistry at Matsudo, Chiba 271-8587
}

(Received 22 October 1999 and accepted 30 March 2000)

\begin{abstract}
The frequencies of oro-maxillo-facial tumors, by type, seen at the Guangxi Medical College Hospital were surveyed in order to compare different regions of the People's Republic of China. Computer analysis was performed on data for all oro-maxillo-facial tumors, as confirmed by the hospital between 1957 and 1987, inclusive. The results were then used in a comparative study with those of five other medical colleges. Among a total of 4,052 cases, there were 1,593 benign tumors, 2,049 malignant tumors and 410 unknown tumors. Tumors derived from the epithelium were the most common type $(42.0 \%$ of the total), whereas in the other five medical colleges the mean corresponding proportion was $27.8 \%$, the difference being significant $(p<0.05)$. Epithelial tumors were also the most common type of malignant tumor (70.5 $\%$ of the total), whereas the corresponding proportion reported by the other five institutions was $60.6 \%$, which was also significantly different $(p<0.05)$. The proportion of malignant tumors among the total was more than $50.6 \%$, which was higher than that reported by the other five colleges. This study shows that epithelium-derived tumors and malignant tumors were encountered more frequently at Guangxi Medical College than at the other five medical colleges in China. (J. Oral Sci. 42, 57-62, 2000)
\end{abstract}

Correspondence to Dr. Kayo Kuyama, Department of Oral Pathology, Nihon University School of Dentistry at Matsudo, 2870-1, Nishi, Matudo, Chiba 271-8587, Japan

Tel. : 047-360-9334, Fax. : 047-360-9335

E-mail address : kayok@mascat.nihon-u.ac.jp
Key words: pathology; People's Republic of China; oro-maxillo-facial tumors; betel nut chewing.

\section{Introduction}

Few epidemiological studies of oro-maxillo-facial tumors in the People's Republic of China have been reported. Malignant tumors in this body region have been shown to be more common than in the rest of the body (1), but no investigation has been conducted in the Guangxi Autonomous District, nor has any study compared its rates of oro-maxillo-facial tumors with other hospitalbased data from the People's Republic of China.

Guangxi Medical College Hospital is located in Nanning, Guangxi Autonomous District, in the southern part of the People's Republic of China, which has a population of about 400 million. It is the only medical college in this district and, with the most highly developed technology of the area, oversees the use of medical facilities. Therefore, the clinical pathology of all the cases treated by this college will likely reflect the distribution of diseases in the area as a whole. Accordingly, the distribution of oro-maxillo-facial tumors dealt with by the college was analyzed from the standpoint of clinical pathology. The results obtained were compared with those from five other medical colleges in China (Huaxi Medical College, Beijing Medical College, Second Shanghai Medical College, Hubei Medical College and The Fourth Military Medical College).

\section{Materials and Methods}

We performed a computer analysis of 4,052 cases of oro- 
maxillo-facial tumors, which had been confirmed by the Department of Oral Pathology, Guangxi Medical College Hospital, from 1957 to 1987. During the 30 years of this study period, all cases were classified histopathologically and/or on the basis on the source of the tumors. The frequency of tumors in each subclassification was estimated with a $98.0 \%$ confidence interval; $2(k+1) \mathrm{F}_{0} / 2(k+1) \mathrm{F}_{0}+2(\mathrm{n}$ $k+1) \geq p \geq 2(\mathrm{n}-k+1) / 2(k+1) \mathrm{F}_{0}+2(\mathrm{n}-k+1)$. Z-tests were used to determine the significance of differences in frequency between classifications and subclassifications.

The histological grading used in this study was based on the "Histological grading of oral soft tissues" by the World Health Organization, 1971 (2). The results were then used in a comparative study with those of the other five medical colleges. The data from these were obtained from a standard oral pathology textbook (3), one of whose editors was also a co-worker in this study. The textbook was compiled from the pathological data collected from the other five medical colleges by the co-worker to ensure data integrity for use in a comparative analysis, and the classifications were checked using it (Tables 1,2). This

Table 1 The classification of odontogenic tumor (Shing, 1986)

\begin{tabular}{|c|c|c|}
\hline \multirow[t]{6}{*}{ Odontogenic epithelium } & Benign & Ameloblastoma \\
\hline & & Odontogenic adenomatoid tumor \\
\hline & & Calcifying epithelial odontogenic tumor \\
\hline & & Calcifying odontogenic cyst \\
\hline & Malignant & Malignant ameloblastoma \\
\hline & & Primary intra-osseous carcinoma \\
\hline \multirow[t]{9}{*}{ Odontogenic ectomesenchyme } & Benign & Odontogenic fibroma \\
\hline & & Odontogenic myxoma \\
\hline & & Dentinoma \\
\hline & & Cementoma \\
\hline & & 1)Benign cementoblastoma \\
\hline & & 2)Periapical cemental dysplasia \\
\hline & & 3)Cementifying fibroma \\
\hline & & 4)Gigantiform cementoma \\
\hline & Malignant & Odontogenic (fibro)sarcoma \\
\hline \multirow{7}{*}{$\begin{array}{l}\text { Odontogenic epithelium } \\
\text { with odontogenic ectomesenchyme }\end{array}$} & Benign & Ameloblastic fibroma \\
\hline & & Ameloblastic odontoma \\
\hline & & Odontoma \\
\hline & & 1)Complex odontoma \\
\hline & & 2)Compound odontoma \\
\hline & Malignant & Ameloblastic fibrosarcoma \\
\hline & & Ameloblastic odontosarcoma \\
\hline
\end{tabular}

enabled us to carry out a valuable comparative epidemiological study.

\section{Results \\ Distribution of oro-maxillo-facial tumors according to tumor source}

Table 3 shows the distribution of all oro-maxillo-facial tumors dealt with at Guangxi Medical College Hospital compared with those of the other five medical colleges in the People's Republic of China, according to tumor source. A total of 4,052 cases were registered, among which odontogenic tumors accounted for $3.6 \%$, salivary gland tumors $20.6 \%$, neurogenic tumors $9.4 \%$ and other types $66.4 \%$. 'Other types' were subdivided into epithelial tumors $(42.0 \%)$, mesenchymal tumors $(24.3 \%)$ and mixed tumors $(0.1 \%)$.

By contrast, among the 20,089 cases seen at the other five medical college hospitals during the same period, 4.8 $\%$ were odontogenic tumors, $22.8 \%$ were salivary gland tumors, $9.7 \%$ were neurogenic tumors and $62.7 \%$ were other types. 'Other types' was subdivided into epithelial

Table 2 The classification of salivary gland tumor (Shing, 1986)

\begin{tabular}{|c|c|c|}
\hline \multirow[t]{13}{*}{ Epithelial tumor } & Benign & Pleomorphic adenoma \\
\hline & & Oxyphilic adenoma \\
\hline & & Adenolymphoma \\
\hline & & Basal cell adenoma \\
\hline & & Papillary cystadenoma \\
\hline & Malignant & Malignant pleomorphic adenoma \\
\hline & & Adenoid cystic carcinoma \\
\hline & & Acinic cell carcinoma \\
\hline & & Mucoepidermoid carcinoma \\
\hline & & Papillary cystadenocarcinoma \\
\hline & & Adenocarcinoma \\
\hline & & Squamous cell carcinoma \\
\hline & & Undifferentiated carcinoma \\
\hline \multirow[t]{8}{*}{ Ectomesenchymal tumor } & Benign & Fibroma \\
\hline & & Lipoma \\
\hline & & Haemangioma \\
\hline & & Lymphangioma \\
\hline & & Neurofibroma \\
\hline & Malignant & Fibrosarcoma \\
\hline & & Malignant lymphoma \\
\hline & & Malignant melanoma \\
\hline
\end{tabular}

Table 3 The source of origin about oral tumors in the Guangxi Medical College Hospital compared with other five medical colleges in China

Guangxi

\begin{tabular}{|c|c|c|c|c|c|c|c|c|}
\hline & & \multicolumn{3}{|c|}{ Guangxı } & \multicolumn{4}{|c|}{ Other five medical colleges } \\
\hline The source of origin & Subdivided group & Number & Percentage $(\%)$ & Appearance rate(\%) & & Number & Percentage $(\%)$ & Appearance rate $(\%)$ \\
\hline Odontogenic tumors & & 146 & 3.6 & $2.8 \sim 7.6$ & ** & 973 & 4.8 & $4.4 \sim 5.5$ \\
\hline Salivary gland tumors & & 833 & 20.6 & $20.6 \sim 22.3$ & ** & 4,569 & 22.8 & $20.9 \sim 25.3$ \\
\hline Neurogenic tumors & & 381 & 9.4 & $8.6 \sim 9.4$ & n.s. & 1941 & 9.7 & $8.8 \sim 10.9$ \\
\hline & Mesenchymal tumors & 984 & 24.3 & $22.4 \sim 24.3$ & ** & 6,979 & 34.7 & $32.4 \sim 37.9$ \\
\hline & Mixed tumors & 6 & 0.1 & $0.1 \sim 0.3$ & n.s. & 39 & 0.2 & $0.1 \sim 0.3$ \\
\hline Total & & 4,052 & 100.0 & & & 20,089 & 100.0 & \\
\hline
\end{tabular}


tumors (27.8\%), mesenchymal tumors (34.7\%) and mixed tumors $(0.2 \%)$. The proportion of epithelial tumors relative to all oro-maxillo-facial tumors dealt with at Guangxi Medical College Hospital was significantly higher, while the rates of odontogenic, salivary gland and mesenchymal tumors were significantly lower than those of the other five medical colleges $(p<0.05)$.

\section{Distribution of tumor types in the subclassifications}

A histological breakdown of odontogenic tumors (146 cases) seen at Guangxi Medical College Hospital (Table 4) showed that the most common tumor type was ameloblastoma $(80.8 \%, p<0.01)$, followed by odontoma and cementifying fibroma $(5.5 \%)$. The histological breakdown of salivary gland tumors ( 833 cases) in this hospital (Table 5) showed that the most common tumor was pleomorphic adenoma $(40.2 \%, p<0.05)$, followed by adenocarcinoma $(16.1 \%)$, malignant pleomorphic adenoma $(11.0 \%)$ and adenoid cystic carcinoma $(8.8 \%)$. Of the neurogenic tumors (381 cases, including

Table 4 Histologic classification of odontogenic tumors in this hospital

\begin{tabular}{llrrr} 
& Histologic classification & Number & Percentage(\%) & Appearance rate(\%) \\
\hline Benign & Ameloblastoma & 118 & 80.8 & $71.7 \sim 87.3$ \\
Odontoma & 8 & 5.5 & $2.5 \sim 12.1$ \\
Cementifying fibroma & 8 & 5.5 & $2.5 \sim 12.1$ \\
Ameloblastic odontoma & 4 & 2.7 & $0.9 \sim 7.9$ \\
Ameloblastic fibroma & 1 & 0.7 & $0.1 \sim 4.5$ \\
Odontogenic myxoma & 1 & 0.7 & $0.1 \sim 4.5$ \\
Odontogenic fibroma & 1 & 0.7 & $0.1 \sim 4.5$ \\
Malignant & Odontogenic fibrosarcoma & 3 & 2.0 & $0.6 \sim 6.8$ \\
Odontogenic myxosarcoma & 2 & 1.4 & $0.3 \sim 5.7$ \\
\hline Total & 146 & 100.0 &
\end{tabular}

Table 5 Histological classification of salivary gland tumors in this hospital

\begin{tabular}{crrrr} 
& Histological classification & Number & Percentage $(\%)$ & Appearance rate $(\%)$ \\
\hline Epitherial Benign & Pleomorphic adenoma & 335 & 40.2 & $36.2 \sim 44.6$ \\
& Adenolymphoma & 21 & 2.5 & $2.4 \sim 2.9$ \\
& Adenoma & 21 & 2.5 & $2.4 \sim 2.9$ \\
Papillary cystadenoma & 10 & 1.2 & $0.6 \sim 2.5$ \\
Oxyphilic adenoma & 1 & 0.1 & $0.0 \sim 0.2$ \\
Malignant & Adenocarcinoma & 134 & 16.1 & $14.8 \sim 17.6$ \\
Malignant pleomorphic adenoma & 92 & 11.0 & $8.9 \sim 19.4$ \\
Adenoid cystic carcinoma & 73 & 8.8 & $6.8 \sim 11.9$ \\
Mucoepidermoid carcinoma & 65 & 7.8 & 5.9 & $\sim 10.6$ \\
Squamous cell carcinoma & 29 & 3.5 & $2.3 \sim 5.4$ \\
Acinic cell carcinoma & 21 & 2.5 & $1.5 \sim 4.2$ \\
Undifferentiated carcinoma & 19 & 2.3 & $1.3 \sim 3.8$ \\
Papillary cystadenocarcinoma & 12 & 1.4 & $0.7 \sim 2.8$ \\
\hline Total & 833 & 100.0 &
\end{tabular}

Table 6 Histological classification of neurogenic tomors in this hospital

\begin{tabular}{|c|c|c|c|c|}
\hline & Histological classification & Number & Percentage $(\%)$ & Appearance rate(\%) \\
\hline \multirow[t]{3}{*}{ Benign } & Pigmented nevus & 256 & 67.2 & $59.2 \sim 74.4$ \\
\hline & Neurofibroma & 60 & 15.8 & $12.0 \sim 21.3$ \\
\hline & Neurilemmoma & 33 & 8.7 & $5.9 \sim 12.6$ \\
\hline \multirow[t]{2}{*}{ Malignant } & Malignant melanoma & 18 & 4.7 & $2.7 \sim 7.9$ \\
\hline & Neurofibrosarcoma & 9 & 2.4 & $1.1 \sim 4.9$ \\
\hline Unknown & & 5 & 1.3 & $0.4 \sim 3.4$ \\
\hline
\end{tabular}

melanogenic tumors), the most common tumor type was pigmented nevus $(67.2 \%)$, followed by neurofibroma $(15.8 \%)$ and neurilemmoma (8.7\%) (Table 6).

Squamous cell carcinoma, which accounted for about $80 \%$ of all epithelial tumors, was the most common of this type of tumor $(1,347$ cases, $p<0.01)$, followed by papilloma $(8.2 \%)$ and basal cell carcinoma $(3.8 \%)$ (Table 7). Among the mesenchymal tumors (984 cases, Table 8 1), the most common tumor type was hemangioma ( 33.7 $\%)$, followed by lymphangioma ( $10.0 \%)$ and non-Hodgkin lymphoma $(8.8 \%)$. Furthermore, the most common histogenesis of mesenchymal tumors (Table 8-2) was vascular tissue $(50.2 \%)$, followed by bony tissue $(17.4 \%)$, lymphoreticular tissue $(13.0 \%)$, and fibrous tissue $(10.2 \%)$.

Distribution of malignant tumors according to histological classification

Table 9 shows the distribution of the malignant oromaxillo-facial tumors seen at Guangxi Medical College Hospital compared with those seen at the other five medical colleges, according to histological classification. A total

Table 7 Histological classification of epithelial tumors in this hospital

\begin{tabular}{llrrr} 
& Histological classification & Number & Percentage $(\%)$ & Appearance rate $(\%)$ \\
\hline Benign & Papilloma & 140 & 8.2 & $6.4 \sim 10.4$ \\
& Verruca senilis & 58 & 3.4 & $2.5 \sim 4.7$ \\
Malignant & Squamous cell carcinoma & 1,347 & 79.2 & $76.1 \sim 81.8$ \\
& Basal cell carcinoma & 64 & 3.8 & $2.8 \sim 5.2$ \\
& Anaplastic carcinoma & 37 & 2.2 & $1.5 \sim 3.2$ \\
Unknown & 56 & 3.3 & $2.4 \sim 4.5$ \\
\hline \multicolumn{2}{c}{ Total } & 1,702 & 100.0 &
\end{tabular}

Table 8-1 Histological classification of mesenchymal tumors in this hospital

\begin{tabular}{llrrr} 
& Histological classification & Number & Percentage(\%) & Appearance rate(\%) \\
\hline Benign & Hemangioma & 333 & 33.7 & $31.6 \sim 37.9$ \\
& Lymphangioma & 98 & 10.0 & $8.0 \sim 12.2$ \\
& Osteofibloma & 51 & 5.2 & $3.7 \sim 7.0$ \\
& Fibroma & 35 & 3.6 & $2.4 \sim 5.1$ \\
Malignant & Fibrosarcoma & 31 & 3.2 & $2.1 \sim 4.5$ \\
& Non-Hodgkin lymphoma & 87 & 8.8 & $6.9 \sim 11.0$ \\
Unknown & & 349 & 35.5 & $31.6 \sim 35.5$ \\
\hline \multicolumn{2}{c}{} & Total & 984 & 100.0
\end{tabular}

Table 8-2 The source of origin about mesenchymal tumors in this hospital

\begin{tabular}{lrrr}
\multicolumn{1}{c}{ Histogenesis } & Number & Percentage(\%) & Appearance rate(\%) \\
\hline Vascular tissue & 494 & 50.2 & $46.1 \sim 52.8$ \\
Fibrous tissue & 100 & 10.2 & $8.2 \sim 12.5$ \\
Bony tissue & 171 & 17.4 & $15.1 \sim 21.8$ \\
Lymphoreticular tissue & 128 & 13.0 & $10.5 \sim 15.8$ \\
Others & 91 & 9.2 & $7.4 \sim 11.4$ \\
\hline Total & 984 & 100.0 &
\end{tabular}


of 2,049 cases (50.6\% of all cases) were registered. Tumors classified as other types of epithelial tumors were the most common $(70.5 \%)$, followed by salivary gland tumors $(21.7 \%)$, and mesenchymal tumors $(5.7 \%)$. Squamous cell carcinoma was the most common epithelial tumor, comprising $33.2 \%$ of all oro-maxillo-facial tumors, and $65.7 \%$ of all malignant tumors. Of the 7,573 cases (37.7\% of all cases) registered at the other five medical colleges during the same period, epithelial tumors of other types were most common $(60.6 \%)$, followed by salivary gland tumors $(25.4 \%)$ and mesenchymal tumors $(11.8 \%)$. Squamous cell carcinoma accounted for $19.0 \%$ of all oro-maxillo-facial tumors, and $50.3 \%$ of all malignant tumors. Epithelial tumors were significantly more common, and salivary gland tumors significantly less common at Guangxi Medical College Hospital than at the other five medical colleges $(p<0.05)$. Of malignant tumors $(2049$ cases) at Guangxi Medical College Hospital, the most common tumor type was carcinoma ( $92.4 \%$ ), followed by sarcoma $(7.4 \%)$ and carcinosarcoma $(0.2 \%)$. Of the 7,573 cases at the other five medical colleges, the most common tumor type was carcinoma (86.1\%), followed by sarcoma $(13.4 \%)$, and carcinosarcoma (0.5\%) (Table 10).

\section{Discussion}

The number of oro-maxillo-facial tumors overall during the three decades of this study, 1957 to 1987, was less than that in Changsha Province during the two decades, 1961 to 1981 (1). The number of cases per year seen at Guangxi Medical College Hospital was only about $36 \%$ of that seen at Changsha. One possible explanation for this difference is that the population of Guangxi Autonomous District is less than that of Changsha Province: 817,331 and 1,227,535, respectively (4). The proportions of epithelial tumors (according to histological classification) and malignancy dealt with at Guangxi Medical College Hospital were larger than those reported by the other five medical colleges, and this is also of interest in relation to the connection between the ethnology of pathogenesis and epidemiologic oncology. The formation of tumor cells results from the action of both intrinsic and extrinsic factors (5). The most strongly suspected intrinsic factors include genetic differences, the effects of nutritional deficiencies, internal secretion and/or climate. The high incidences of salivary tumors in Eskimos, ameloblastoma in Africans and Koreans, and oral cancer in Indians, is related to racial predisposition, for example (6)

Extrinsic factors include various occupational and habitual stimuli associated with lifestyle. Most people who chew betel nuts live in South and South-east Asia (79 ), which has an estimated $10-25 \%$ of the world's population (7). Addiction to betel nut must be widespread in Guangxi Autonomous District because this district is located in the southern part of China, being more southerly than the other five provinces investigated in this study, and also close to Hainan Island and Hunan Province, where betel addiction is very common $(10,11)$. The habit of betel nut chewing is known from epidemiology to be an important etiological factor for oral submucosal fibrosis (OSF) $(10,12)$ and to induce high-risk precancerous conditions (10) and/or oral cancer (13). If the entire population of China is considered to have descended from the ancient Han race, then extrinsic factors should also be considered; however, very many kinds of racial minorities are living

Table 9 The source of origin about oral malignant tumors in the Guangxi Medical College Hospital compared with other five medical colleges in China

\begin{tabular}{|c|c|c|c|c|c|c|c|c|}
\hline \multirow[b]{2}{*}{ The source of origin } & \multirow[b]{2}{*}{ Subdivided group } & \multicolumn{3}{|c|}{ Guangxi } & \multicolumn{4}{|c|}{ Other five medical colleges } \\
\hline & & Number & Percentage(\%) & Appearance rate $(\%)$ & & Number & Percentage(\%) & Appearance rate $(\%)$ \\
\hline Odontogenic tumors & & 5 & 0.2 & $0.1 \sim 0.3$ & n.s. & 8 & 0.1 & $0.0 \sim 0.2$ \\
\hline Salivary gland tumors & & 445 & 21.7 & $20.0 \sim 21.7$ & ** & 1,923 & 25.4 & $22.3 \sim 28.8$ \\
\hline Neurogenic tumors & & 27 & 1.6 & $1.1 \sim 2.3$ & n.s. & 150 & 2.0 & $1.6 \sim 2.5$ \\
\hline Others & Epithelial tumors & 1,448 & 70.5 & 70.5 & ** & 4,592 & 60.6 & $56.4 \sim 64.7$ \\
\hline & Mesenchymal tumors & 118 & 5.7 & $4.6 \sim 7.1$ & n.s. & 896 & 11.8 & $11.5 \sim 16.0$ \\
\hline & Mixed tumors & 6 & 0.3 & $0.1 \sim 0.7$ & n.s. & 4 & 0.1 & $0.0 \sim 0.2$ \\
\hline Total & & 2,049 & 100.0 & & & 7,573 & 100.0 & \\
\hline
\end{tabular}

Table 10 Histological classification of malignant tumors in this hospital compared with other five medical colleges in China

\begin{tabular}{|c|c|c|c|c|c|c|}
\hline \multirow[b]{2}{*}{ Histological classificatior } & \multicolumn{3}{|c|}{ Guangxi } & \multicolumn{3}{|c|}{ Other five medical colleges } \\
\hline & Number & Percentage $(\%)$ & Appearance rate $(\%)$ & Number & Percentage $(\%)$ & Appearance rate $(\%)$ \\
\hline Carcinoma & 1,893 & 92.4 & $90.6 \sim 93.5 * *$ & 6,523 & 86.1 & $78.0 \sim 87.3$ \\
\hline Sarcoma & 152 & 7.4 & $5.9 \sim 15.0$ & 1,011 & 13.4 & $12.2 \sim 14.6$ \\
\hline Carcinosarcoma & 4 & 0.2 & $0.1 \sim 0.6$ n.s. & 39 & 0.5 & $0.4 \sim 0.5$ \\
\hline Total & 2,049 & 100.0 & & 7,573 & 100.0 & \\
\hline
\end{tabular}


throughout China at present, and the people of Guangxi Autonomous District - Zhuangs - are one of them (14). Epstein-Barr virus may be one extrinsic factor, because all Asian patients with nasopharyngeal carcinoma are seropositive for Epstein-Barr virus (15). This study showed a relatively high incidence of oral epithelial tumors and malignancy in the study area, and any multifactorial analysis will need to consider several possible contributory factors, as described above.

The frequency of ameloblastoma, which accounted for most odontogenic tumors, was similar to that reported in previous studies of Asian populations (16-19). On the other hand, there is geographic variation in the incidence of ameloblastoma $(8,20)$. Wu and Chan (16) thought that this variation might be partly the result of controversy about the terminology and classification of odontogenic tumors. By contrast, the lower frequency of odontogenic tumors (6) compared with all tumors was due to the larger proportion of epithelial tumors in this study series.

As mentioned above, more than $50 \%$ of the tumors surveyed were malignant. This is higher than the figure of $26.2 \%$ for tumors in the body as a whole (3). The present findings also indicate that the frequency of oro-maxillofacial malignant tumors is relatively high, in agreement with previous studies $(3,21,22)$.

Although a large number of epidemiological studies have investigated oro-maxillo-facial tumors, the precise definition of the term 'oro-maxillo-facial tumors' has not yet been standardized. This problem applies without exception to all reports about these types of tumors in the Chinese population, and therefore a degree of uncertainty in comparative studies has remained. To overcome this problem, we had one co-worker collect the data from the other five medical colleges with the aim of standardizing the term 'oro-maxillo-facial tumors'. This original approach enabled us to carry out a useful comparative epidemiological study of oro-maxillo-facial tumors and obtain valuable results.

\section{Acknowledgments}

The authors are indebted to all staff at the Department of Oral Pathology of Huaxi Medical College, Beijing Medical College, Second Shanghai Medical College, Hubei Medical College and The Fourth Military Medical College for their cooperation and supply of valuable pathological data. This work was supported in part by a grant for Frontier Science from the Ministry of Education, Science, Sports and Culture of Japan (Nihon University School of Dentistry at Matsudo) and by a Suzuki Research Grant from Nihon University School of Dentistry at Matsudo.

\section{References}

1. You, M.G. (1989) Analysis of 7878 patients with tumors in the head and neck. Chung Hua Chung Lin Tsa Chih. 11, 282-287 (in Chinese)

2. Wahi, P.N., Cohen, B., Luthra, U.K. and Torloni, H. (1971) Histological typing of oral and oropharyngeal tumours. In International histological classification of tumours No.4. World Health Organization ed., Geneva, 9-27

3. Shing, C.R. (1986) Oral histopathology. People's hygienic publication, Beijing, 184-228 (in Chinese)

4. United Nations (1995) 1993 Demographic Yearbook. United Nations, New York, 200-207

5. Waldron, C.A. (1970) Oral epithelial tumors. In Thoma's oral pathology. Vol.2, Gorlin, R.J. and Goldman, H.M. eds., The C.V. Mosby Company, St. Louis, 801-860

6. Arotiba, J.T., Ogunbiyi, J.O. and Obiechina, A.E. (1997) Odontogenic tumours: a 15-year review from Ibadan, Nigeria. Br. J. Oral Maxillofac. Surg. 35, 363-367

7. Pickwell, S.M., Schimelpfening, S. and Palinkas, L. A. (1994) 'Betelmania'. Betel quid chewing by Cambodian women in the United States and its potential health effects. West. J. Med. 160, 326330

8. Summers, R.M., Williams, S.A. and Curzon, M.E. (1994) The use of tobacco and betel quid ('pan') among Bangladeshi women in West Yorkshire. Community Dent. Health 11, 12-16

9. Strickland, S.S. and Duffield, A.E. (1997) Anthropometric status and resting metabolic rate in users of the areca nut and smokers of tobacco in rural Sarawak. Ann. Hum. Biol. 24, 453-474

10. Tang, J.G., Jian, X.F., Gao, M.L., Ling, T.Y. and Zhang, K.H. (1997) Epidemiological survey of oral submucous fibrosis in Xiangtan City, Hunan Province, China. Community Dent. Oral Epidemiol. $25,177-180$

11. Pindborg, J.J., Zheng, K.H., Kong, C.R. and Ling, F.X. (1984) Pilot survey of oral mucosa in areca (betel) nut chewers on Hainan Island of the People's Republic of China. Community Dent. Oral Epidemiol. 12, 195-196

12. Murti, P.R., Gupta, P.C., Bhonsle, R.B., Daftary, D.K., Mehta, F.S. and Pindborg, J.J. (1990) Effect on the incidence of oral submucous fibrosis of intervention in the areca nut chewing habit. J. Oral Pathol. Med. 19, 99-100

13. Kuo, M.Y., Jeng, J.H., Chiang, C.P. and Hahn, L.J. 
(1994) Mutations of Ki-ras oncogene coden 12 in betel quid chewing-related human oral squamous cell carcinoma in Taiwan. J. Oral Pathol. Med. 23, 7074

14. Xu, J.J., Cui, M.Y., Li, S.Z., Chen, L.Z., Du, R.F., Goedde, H.W., Benkmann, H.G., Kriese, L. and Bogdanski, P. (1986) Polymorphisms of Pi, Hp, ADA and AK in Mongolian, Korean and Zhuang populations of China. Ann Hum Biol. 13, 245-251

15. Epstein, J.B., Emerton, S., Lunn, R., Le, N. and Wong, F.L. (1999) Pretreatment assessment and dental management of patients with nasopharyngeal carcinoma. Oral Oncol. 35, 33-39

16. Wu, P.C. and Chan, K.W. (1985) A survey of tumours of the jawbones in Hong Kong Chinese: 1963-1982. Br. J. Oral Maxillofac. Surg. 23, 92-102

17. Chung, D.H., Kinnman, J.E. G., Lee, B.C. and Lee, Y.T. (1969) Tumors of the jaws in Korea. Report of 157 cases. Oral Surg. Oral Med. Oral Pathol. 27, 716728
18. Reddy, C.R.R.M. (1974) Incidence of jaw tumors on the east coast of South India. Int. Surg. 59, 400401

19. Gunhan, O., Erseven, G., Ruacan, S., Celasun, B., Aydintug, Y., Ergun, E. and Demiriz, M. (1990) Odontogenic tumours. A series of 409 cases. Aust. Dent. J. 35, 518-522

20. Lu, Y., Xuan, M., Takata, T., Wang, C., He, Z., Zhou, Z., Mock, D. and Nikai, H. (1998) Odontogenic tumors. A demographic study of 759 cases in a Chinese population. Oral Surg. Oral Med. Oral Pathol Oral Radiol. Endod. 86, 707-714

21. Thongsuksai, P., Sriplung, H., Phungrassami, T. and Prechavittayakul, P. (1997) Cancer incidence in Songkhla, southern Thailand, 1990-1994. Southeast Asian J. Trop. Med. Public Health 28, Suppl.3 110

22. Pindborg, J.J. (1977) Epidemiological studies of oral cancer. Int. Dent. J. 27, 172-178 